\title{
Recurrence and survival after pathologic complete response to preoperative therapy followed by surgery for gastric or gastrooesophageal adenocarcinoma
}

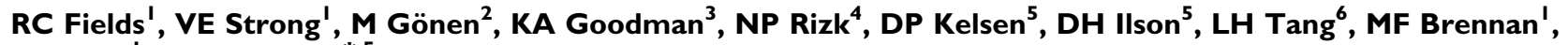 \\ DG Coit' and MA Shah*,5
}

'Gastric and Mixed Tumor Service, Department of Surgery, Memorial Sloan-Kettering Cancer Center, New York, NY I0065, USA; ${ }^{2}$ Department of Epidemiology and Biostatistics, Memorial Sloan-Kettering Cancer Center, New York, NY 10065, USA; ${ }^{3}$ Department of Radiation Therapy, Memorial Sloan-Kettering Cancer Center, New York, NY 10065, USA; ${ }^{4}$ Thoracic Service, Department of Surgery, Memorial Sloan-Kettering Cancer Center, New York, NY 10065, USA; ${ }^{5}$ Gastrointestinal Oncology Service, Department of Medicine, Memorial Sloan-Kettering Cancer Center, 1275 York Avenue, Box 314, New York, NY 10065, USA; ${ }^{6}$ Gastrointestinal Pathology Senvice, Department of Pathology, Memorial Sloan-Kettering Cancer Center, New York, NY 10065, USA

BACKGROUND: To characterise recurrence patterns and survival following pathologic complete response ( $p C R$ ) in patients who received preoperative therapy for localised gastric or gastrooesophageal junction (GEJ) adenocarcinoma.

METHODS: A retrospective review of a prospective database identified patients with $\mathrm{PCR}$ after preoperative chemotherapy for gastric or preoperative chemoradiation for GEJ (Siewert II/III) adenocarcinoma. Recurrence patterns, overall survival, recurrence-free survival, and disease-specific survival were analysed.

RESULTS: From 1985 to 2009, 7I4 patients received preoperative therapy for localised gastric/GEJ adenocarcinoma, and 609 (85\%) underwent a subsequent R0 resection. There were 60 patients (8.4\%) with a pCR. Median follow-up was 46 months. Recurrence at 5 years was significantly lower for $\mathrm{pCR}$ vs non-pCR patients $(27 \%$ and $51 \%$, respectively, $P=0.0 \mathrm{I})$. The probability of recurrence for patients with $\mathrm{pCR}$ was similar to non-pCR patients with pathologic stage I or II disease. Although the overall pattern of local/regional (LR) vs distant recurrence was comparable (43\% LR vs $57 \%$ distant) between pCR and non-pCR groups, there was a significantly higher incidence of central nervous system (CNS) first recurrences in pCR patients (36 vs $4 \%, P=0.0$ I).

CONCLUSION: Patients with gastric or GEJ adenocarcinoma who achieve a PCR following preoperative therapy still have a significant risk of recurrence and cancer-specific death following resection. One third of the recurrences in the pCR group were symptomatic CNS recurrences. Increased awareness of the risk of CNS metastases and selective brain imaging in patients who achieve a pCR following preoperative therapy for gastric/GEJ adenocarcinoma is warranted.

British Journal of Cancer (201 I) I 04, I840- 1847. doi:I0.1038/bjc.20 I I.I75 www.bjcancer.com

Published online 24 May 2011

(c) 20II Cancer Research UK

Keywords: gastric cancer; pathologic complete response; surgery; chemotherapy; radiation therapy

Together, gastric and oesophageal adenocarcinoma are the second most common malignancies of the gastrointestinal tract in the United States and worldwide (Kamangar et al, 2006; Jemal et al, 2010). The US age-adjusted incidence and mortality of gastric/ gastrooesophageal junction (GEJ) adenocarcinoma is 7.3 and 5.04 per 100000 persons, respectively, and the incidence of gastric cancer is rising in the United States in the young age bracket (Anderson et al, 2010; Shah and Ajani, 2010). The majority of patients presenting with resectable gastric/GEJ adenocarcinoma

*Correspondence: Dr MA Shah; E-mail: masshah00 I I@gmail.com This study was presented at the 2011 American Society of Clinical Oncology Gastrointestinal Cancers Symposium, 21 January 201I, San Francisco, CA, USA.

Received 17 February 2011; revised 13 April 201 I; accepted 20 April 201 I; published online 24 May 2011 will have locally advanced disease (defined as the penetration of the subserosa by the primary tumour (T3), regional nodal involvement $(\mathrm{N}+)$, or both (Edge et al, 2010)) for which the chance of cure with surgery alone is poor (Hundahl et al, 2000; Wu et al, 2009; Anderson et al, 2010). For these locally advanced cases, several random assignment studies have established additional therapy as the standard of care, including perioperative chemotherapy with or without radiation therapy (RT) (Cunningham et al, 2006; Stahl et al, 2009), or postoperative chemoradiation (Macdonald et al, 2001), highlighting the importance of multidisciplinary care for these patients.

It is well established that pathologic complete response (pCR) following preoperative therapy is associated with improved survival in several malignancies, including breast adenocarcinoma after preoperative chemotherapy $\pm \mathrm{RT}$ (Wolmark et al, 2001; Symmans et al, 2007; Adams et al, 2010; Chavez-Macgregor et al, 2010), oesophageal cancer after preoperative chemoradiotherapy 
(Berger et al, 2005; Rohatgi et al, 2005; Chao et al, 2009; Donahue et al, 2009; Park et al, 2010), lung cancer after preoperative chemoradiotherapy (Mamon et al, 2005; Chen et al, 2007), and rectal cancer after preoperative chemoradiotherapy (Maas et al, 2010). Notably, the $15-27 \%$ rate of pCR after chemoradiotherapy in rectal cancer (Pucciarelli et al, 2004) has led some groups to omit surgery and undertake intensive follow-up in select patients who achieve a clinical complete response with no detectable residual tumour after chemoradiotherapy (Habr-Gama et al, 2004).

The timing and pattern of recurrence and overall patient survival in patients with gastric/GEJ adenocarcinoma achieving a pCR after preoperative multimodality treatment is not well characterised, with the current description limited to a single series of 24 patients with gastric cancer who achieved a pCR following chemoradiation (Reed et al, 2008). Herein, we report our experience in patients with gastric/GEJ adenocarcinoma who received preoperative chemotherapy $\pm \mathrm{RT}$ followed by complete (R0) resection and achieved a pCR. We compare their survival and recurrence to similarly treated patients who did not achieve a pCR.

\section{PATIENTS AND METHODS}

\section{Patients and pretreatment evaluation}

Patients with gastric/GEJ adenocarcinoma who received preoperative therapy were identified from a prospective surgical database at Memorial Sloan-Kettering Cancer Center (MSKCC) from 1985 to 2009. The MSKCC Institutional Review Board approved the study design. Patients with a diagnosis of distal oesophageal carcinoma (Siewert I) were excluded.

Pretreatment evaluation usually consisted of a computed tomography (CT) scan of the abdomen and pelvis, endoscopic ultrasound (EUS), diagnostic laparoscopy with cytologic washings, and selective use of positron emission tomography (PET). We collected patient demographics including age, gender, race, and body mass index; preoperative tumour characteristics including tumour location, pretreatment EUS T-stage, and tumour histology; and preoperative chemotherapy regimen and use of RT.

\section{Treatment}

Preoperative chemotherapy was administered in the outpatient setting and was grouped into: 5 -fluorouracil (5-FU) and platinumbased regimens (including epirubicin + cisplatin or oxaliplatin + 5-FU or capecitabine (ECF/ECX/EOX/EOF), and cisplatin/5-FU), platinum-based regimens (including cisplatin/CPT11), taxanebased regimens (including taxane $+\mathrm{CPT} 11 \pm 5-\mathrm{FU}$ ), and other regimens (including 5 -FU + doxorubicin + methotrexate (FAMTX), mitomycin $\mathrm{C}$, and doxorubicin).

Preoperative radiation was delivered as multifield, externalbeam megavoltage radiation using high-energy linear accelerators ( 6 or $15 \mathrm{MV}$ ). Treatment generally included five daily fractions of 1.8 Gy per week over a 5.5 -week course with a total radiation dose of $50.4 \mathrm{~Gy}$. The superior field border extended $\sim 5 \mathrm{~cm}$ cranial to the tumour, and the inferior border extended caudally to include the coeliac lymph node (LN) region. The anterior, posterior, and lateral field borders were $\sim 2 \mathrm{~cm}$ beyond the tumour, as defined by pretreatment imaging. The locoregional LNs were included in the radiation field.

After preoperative treatment, patients underwent gastrectomy or oesophagogastrectomy with two-field (for oesophagogastrectomy) or D2 (for gastrectomy) lymphadenectomy and splenic preservation whenever possible. A curative (R0) resection was defined as the removal of all visible disease and associated nodal basins with negative microscopic surgical margins on final pathologic review. Pathologic staging is reported according to the American Joint Committee on Cancer staging guidelines (7th edn) for gastric adenocarcinoma (Edge et al, 2010). Surgical treatment characteristics collected included operative and pathologic details, including extent of gastrectomy/oesophagogastrectomy, type of LN dissection, and resected specimen pathologic analysis (T-stage, $\mathrm{N}$-stage, number of LN examined, and pathologic treatment effect).

Follow-up laboratory and imaging studies and additional postoperative treatment were at the discretion of the treating physician(s) or as directed by a patient-enrolled protocol (Kelsen et al, 1992, 1997; Bains et al, 2002; Brenner et al, 2004, 2006; Anderson et al, 2007; Schwartz et al, 2009). Patients were generally followed every 2-3 months for the first 2 years, followed by every 6-12 months thereafter. Recurrence was confirmed radiographically and/or pathologically and described as local/regional (including peritoneal) or distant. Date of recurrence was defined as the first notation in the medical record indicating the recurrence. Disease status at last follow-up and cause of death were determined by the medical record, death certificates, and follow-up correspondence.

\section{Pathology}

Pathologic complete response was defined as fibrosis or fibroinflammation within an entirely submitted and evaluated gross lesion without microscopic evidence of carcinoma, and histologically negative nodes. Non-pCR was defined as any evidence of viable carcinoma, either at the primary site or in the resected regional LN. The pathologic stage of residual carcinoma in the non-pCR group was based on the deepest focus of viable malignant epithelium in the gastric and oesophageal wall and/or any carcinoma found in the LN analysis. Pathologic treatment effect was analysed and quantified on a graded, per cent scale as previously described (Mansour et al, 2007). Positive LNs were defined as the presence of any viable tumour cells within LNs.

\section{Statistical analysis}

Statistical analysis was performed using the $\mathrm{R}$ package, version 2.10 (http://www.r-project.org). Patient, tumour, and treatment variables were compared between the $\mathrm{pCR}$ and non-pCR groups using the $\chi^{2}$ and Wilcoxon rank sum test with continuity correction for categorical and continuous variables, respectively. Recurrence-free survival (RFS) was compared between the pCR and non-pCR groups using the log-rank test. Recurrence location was compared using the $\chi^{2}$ test. Kaplan-Meier methods were used to estimate overall survival (OS), disease-specific survival (DSS), and RFS probability between pCR and non-pCR groups and compared using the log-rank test (Kaplan and Meier, 1958). Death without a recurrence was considered as a competing cause of failure (Prentice et al, 1978; Satagopan et al, 2004). Estimated cumulative incidence of recurrence was performed using the subdistribution method and compared using Gray's test (Gray, 1988).

\section{RESULTS}

From 1985 to 2009, 2676 patients underwent surgical treatment for gastric or GEJ (Siewert II/III) adenocarcinoma at MKSCC. In all, 714 of these patients $(27 \%)$ received preoperative chemotherapy \pm RT. One hundred and five patients $(15 \%)$ had either positive surgical margins after resection (64 patients, $9 \%$ ) or presence of metastatic disease at surgical exploration/resection (41 patients, $6 \%$ ) and were excluded from subsequent analysis. The final study population was 609 patients with gastric/GEJ adenocarcinoma treated with preoperative therapy $(280(46 \%)$ chemoradiotherapy, 329 (54\%) chemotherapy alone) followed by complete (R0) resection. Sixty patients $(8.4 \%$ of all preoperative treatment patients; $10 \%$ of preoperative treatment patients who underwent 


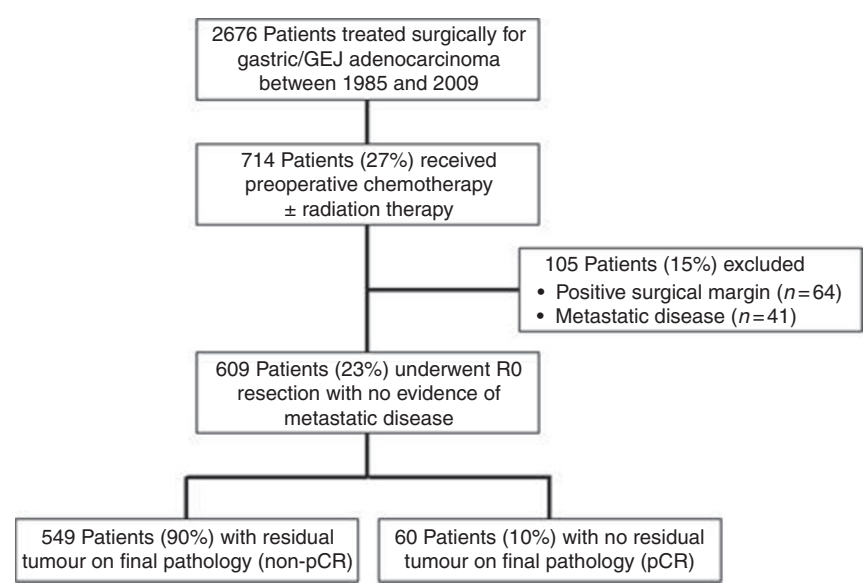

Figure I Patient study group CONSORT diagram.

R0 resection) demonstrated no residual tumour on final pathology and are defined as the pCR group, and the remainder $(n=549$, $90 \%$ of all preoperative treatment patients who underwent R0 resection) had residual evidence of malignancy and are defined as the non-pCR group (Figure 1).

Table 1 lists the patient characteristics of the pCR and non-pCR patients. There were no differences between the $\mathrm{pCR}$ and non-pCR groups with respect to patient age, race, pretreatment EUS T-stage, or histology (Lauren or differentiation). Most patients had advanced T-stage tumours ( $\geqslant 80 \% \mathrm{~T} 3$ for both pCR and nonpCR patients). Forty-seven patients who received chemoradiation $(17 \%)$ achieved a pCR, and $12(26 \%)$ of these patients recurred. Thirteen patients who received chemotherapy alone (4\%) achieved a pCR, and $2(17 \%)$ of these patients recurred. Patients who received taxane-based therapy more commonly also received concurrent radiotherapy and therefore more commonly achieved a pCR.

Table 2 lists the pathologic $\mathrm{T}$ - and $\mathrm{N}$-stages and extent of surgical nodal resection. There were no differences in the extent of LN dissection (D1, D2, or D3) between the pCR and non-pCR groups. The non-pCR patients had a mean of 3.0 (range 1-8) positive LNs and a mean pathologic treatment effect of $45 \%$ (range 10-95). The pCR group had a higher mean number of LNs examined (29 vs 23), $P=0.04$.

Median follow-up for all surviving patients was 46 months (interquartile range $=16-90)$. Of the 549 patients with a non-pCR, $153(28 \%)$ received postoperative (adjuvant) chemotherapy, and of the 60 patients with a pCR, one patient received additional postoperative chemotherapy. Overall survival, DSS, and RFS was significantly greater in the pCR group compared with the non-pCR group (Figure 2). The timing and pattern of recurrences are summarised in Table 3. For patients achieving a pCR, there was no difference in recurrence between patients who received chemoradiotherapy $v s$ chemotherapy alone (26\% and $15 \%$, respectively, $P=0.2)$. While the non-pCR group had a higher risk of recurrence at 1,3 , and 5 years (5-year recurrence $=27$ vs $51 \%$ for pCR and non-pCR, respectively, $P=0.02$ ), the pattern of recurrence was similar. There was no difference in the distribution of local/ regional vs distant recurrences ( $43 \%$ vs $57 \%$, respectively) between pCR and non-pCR groups. However, we did observe a significantly higher incidence of first recurrences in the central nervous system (CNS) in pCR $(36 \%)$ compared with non-pCR $(4 \%)$ patients $(P=0.01)$. All of the patients with a CNS recurrence in the pCR group presented symptomatically (four with seizures and one with localising neurologic symptoms), and similarly 8 of the 10 patients $(4 \%)$ in the non-pCR group who initially recurred in the CNS presented symptomatically (seven with seizures and one with localising neurologic symptoms).
Table I Patient, tumour, and preoperative treatment variables in patients undergoing preoperative chemotherapy \pm radiation therapy for gastric and gastrooesophageal junction adenocarcinoma, followed by R0 resection

\begin{tabular}{|c|c|c|c|}
\hline \multirow[b]{2}{*}{ Variable } & \multicolumn{2}{|c|}{ Number (\%) } & \multirow[b]{2}{*}{$P$-value ${ }^{a}$} \\
\hline & $\begin{array}{c}\text { Non-pCR } \\
\text { patients } \\
(n=549)\end{array}$ & $\begin{array}{c}\text { PCR } \\
\text { patients } \\
(n=60)\end{array}$ & \\
\hline Age (median, IQR) & $62(54-69)$ & $64(56-69)$ & $0.18^{\mathrm{b}}$ \\
\hline Preoperative BMI (median, IQR) & $27(24-30)$ & $28(25-32)$ & $0.04^{b}$ \\
\hline \multicolumn{4}{|l|}{ Gender } \\
\hline Male & $403(73)$ & $52(87)$ & 0.02 \\
\hline Female & 146 (27) & $8(13)$ & \\
\hline \multicolumn{4}{|l|}{ Race } \\
\hline Caucasian & 487 (89) & $57(95)$ & \\
\hline African-American & $24(4)$ & $1(2)$ & 0.64 \\
\hline Asian/Pacific Islander & $31(6)$ & $2(3)$ & \\
\hline Other/unknown & $7(1)$ & $0(0)$ & \\
\hline \multicolumn{4}{|l|}{ Tumour location } \\
\hline GEJ & $312(57)$ & $47(78)$ & \\
\hline Gastric, proximal & $74(13)$ & $6(10)$ & \\
\hline Gastric, body & $71(13)$ & $4(7)$ & 0.02 \\
\hline Gastric, distal & $85(15)$ & $3(5)$ & \\
\hline Gastric, diffuse & $7(1)$ & $0(0)$ & \\
\hline \multicolumn{4}{|l|}{ Pretreatment EUS T-stage } \\
\hline $\mathrm{TI}$ & $4(1)$ & $0(0)$ & \\
\hline $\mathrm{T} 2$ & $72(13)$ & $10(17)$ & \\
\hline T3 & $447(81)$ & $50(83)$ & 0.43 \\
\hline T4 & $15(3)$ & $0(0)$ & \\
\hline Not performed & $11(2)$ & $0(0)$ & \\
\hline \multicolumn{4}{|l|}{ Histology - Lauren classification } \\
\hline Diffuse & $169(31)$ & $19(32)$ & \\
\hline Intestinal & $333(61)$ & $39(65)$ & 0.62 \\
\hline Mixed & $47(9)$ & $2(3)$ & \\
\hline \multicolumn{4}{|l|}{ Histology - differentiation } \\
\hline Well & $12(2)$ & $3(5)$ & \\
\hline Moderate & $207(38)$ & $14(23)$ & 0.25 \\
\hline Poor & $330(60)$ & $43(72)$ & \\
\hline \multicolumn{4}{|l|}{ Preoperative chemotherapy regimen } \\
\hline 5-FU and platinum based & $221(39)$ & $23(34)$ & \\
\hline Platinum based & 157 (27) & $15(22)$ & 0.0007 \\
\hline Taxane based & $130(23)$ & $28(4 I)$ & \\
\hline Other & $65(11)$ & $2(3)$ & \\
\hline \multicolumn{4}{|l|}{ Preoperative radiation treatment } \\
\hline Yes & $233(42)$ & $47(78)$ & $<0.0001$ \\
\hline
\end{tabular}

Abbreviations: 5-FU = 5-fluorouraci; BMI = body mass index; $\mathrm{GEJ}=$ gastrooesophageal junction; $\mathrm{IQR}$ = interquartile range; $\mathrm{PCR}=$ pathologic complete response; $E U S$ = endoscopic ultrasound. ${ }^{a} \chi^{2}$ text, except where otherwise noted by 'b. ' ${ }^{b}$ Wilcoxon rank sum test with continuity correction. Bold values indicate significant differences.

Figure 3 summarises the probability of recurrence by final pathologic stage when treating death from other causes as a competing risk. When compared with pCR patients, the probability of recurrence is significantly higher only for pathologically stage III (pIII) non-pCR patients (5-year CI of recurrence $=74 v \mathrm{~s}$ $27 \%, P<0.001)$. Among the pIII patients, although the majority were stage III by virtue of residual nodal involvement, the three node negative (i.e., T4N0) pIII patients also had a high risk of recurrence, each one developing recurrence within 1 year of resection. There is no significant difference in the probability of 
Table 2 Pathologic variables in patients undergoing preoperative chemotherapy \pm radiation therapy for gastric and gastrooesophageal junction adenocarcinoma, followed by $\mathrm{RO}$ resection

\begin{tabular}{|c|c|c|c|}
\hline \multirow[b]{2}{*}{ Variable } & \multicolumn{2}{|c|}{ Number (\%) } & \multirow[b]{2}{*}{$P$-value } \\
\hline & $\begin{array}{c}\text { Non-pCR } \\
\text { patients } \\
(n=549)\end{array}$ & $\begin{array}{c}\text { PCR } \\
\text { patients } \\
(n=60)\end{array}$ & \\
\hline \multicolumn{4}{|l|}{ pT stage $\mathrm{a}^{\mathrm{a}}$} \\
\hline$T 0^{\mathrm{b}}$ & $\|(2)$ & $60(100)$ & \\
\hline Tla & $21(4)$ & 0 & \\
\hline Tlb & $48(9)$ & 0 & \\
\hline $\mathrm{T} 2$ & $125(23)$ & 0 & N/A \\
\hline T3 & $243(44)$ & 0 & \\
\hline T4a & $93(17)$ & 0 & \\
\hline T4b & $8(1)$ & 0 & \\
\hline \multicolumn{4}{|l|}{ pN stage ${ }^{a}$} \\
\hline NO & $241(44)$ & $60(100)$ & \\
\hline $\mathrm{NI}$ & $131(24)$ & 0 & \\
\hline N2 & $97(18)$ & 0 & N/A \\
\hline N3a & $59(11)$ & 0 & \\
\hline N3b & $21(4)$ & 0 & \\
\hline \multicolumn{4}{|c|}{ Extent of surgical lymphadenectomy } \\
\hline DI & $20(4)$ & । (2) & \\
\hline D2 & $513(93)$ & $57(95)$ & $0.72^{c}$ \\
\hline D3 & $16(3)$ & $2(3)$ & \\
\hline $\begin{array}{l}\text { Number of positive } L N \\
\text { (for } \geqslant N I \text { : mean, } I O R \text { ) }\end{array}$ & $3.0(1-8)$ & $0(0)$ & N/A \\
\hline $\begin{array}{l}\text { Number of } L N \text { examined } \\
\text { (mean, } I O R \text { ) }\end{array}$ & $23(15-29)$ & $29(25-32)$ & $0.04^{\mathrm{d}}$ \\
\hline $\begin{array}{l}\text { Pathologic treatment effect } \\
\text { (mean \%, IQR) }\end{array}$ & $45(10-95)$ & 100 & N/A \\
\hline
\end{tabular}

Abbreviations: $\mathrm{IQR}=$ interquartile range; $\mathrm{LN}=$ lymph node; $N / \mathrm{A}=$ not applicable (no statistical analysis performed, as differences are defined by subgroup stratification); $\mathrm{pCR}=$ pathologic complete response. ${ }^{\mathrm{a}} \mathrm{AJCC}$ 7th edn, $20 \mathrm{IO}$. ${ }^{\mathrm{b}} \mathrm{TONI}$ $(n=9)$ and TON2 $(n=2)-1$ patient has recurred after a median follow-up of 17 months. ${ }^{c} \chi^{2}$ text. ${ }^{d}$ Wilcoxon rank sum test with continuity correction. Bold values indicate significant differences.

recurrence between $\mathrm{pCR}$ patients and stage pI or stage pII non-pCR patients (5-year CI of recurrence $=39 \%$ and $25 \%$, respectively, $P=0.49$ for pCR $v s$ non-pCR stage $\mathrm{I}$ and $P=0.36$ for PCR $v s$ non-pCR stage II).

Table 4 provides clinical characteristics of those patients with pCR who developed recurrence $(n=14,23 \%)$. Five patients $(36 \%$ of pCR recurrences; $8 \%$ of all pCR patients) developed CNS recurrence as their first site of recurrence, with a mean time to recurrence of 12.6 \pm 7.7 months (range 5-24 months). Treatment after CNS recurrence consisted of whole brain RT in two patients, surgery (craniotomy) in one patient, and no treatment in two patients. All five pCR patients with CNS recurrences died of their disease, with a mean time from recurrence to death of 9.6 months (range $=2-26$ months). Of note, 6 of the 14 pCR patients that recurred (43\%) had local/regional recurrence (anastomotic or regional nodal), all of whom received preoperative chemoradiation.

\section{DISCUSSION}

In the past 10 years, results of several randomised controlled trials have established multimodality therapy as the standard of care for locally advanced gastric/GEJ adenocarcinoma (Macdonald et al, 2001; Cunningham et al, 2006; Stahl et al, 2009; Schuhmacher et al, 2010). Reflective of the multidisciplinary approach to locally advanced gastric and GEJ adenocarcinoma, we describe the outcome of patients who received preoperative chemotherapy or
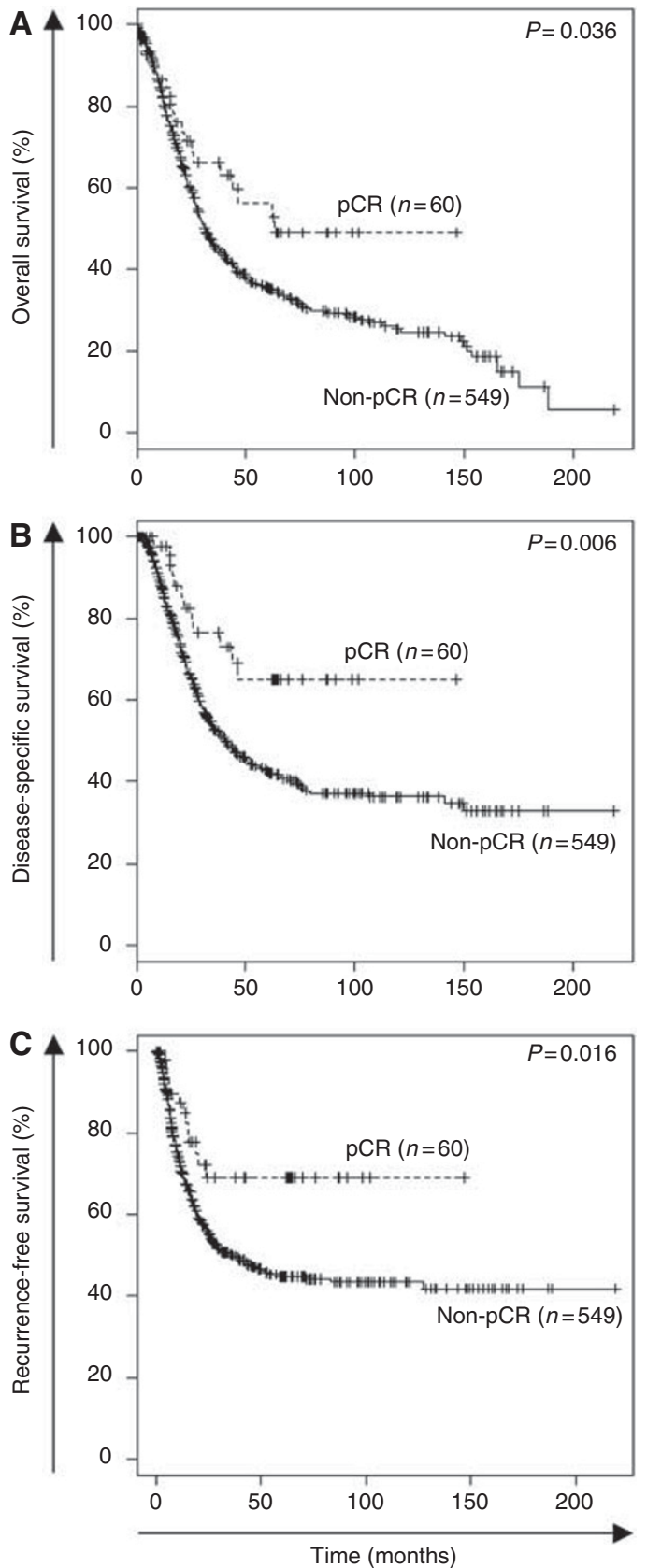

Figure 2 Kaplan-Meier estimates of overall (A), disease-specific (B), and recurrence-free $(\mathbf{C})$ survival stratified by pathologic complete response (PCR) vs non-pathologic complete response (non-pCR). Statistical comparisons between PCR and non-pCR groups were determined using the log-rank test.

chemoradiation followed by complete surgical resection and who achieved a pCR to preoperative therapy. We found a $10 \%$ pCR rate in patients with gastric/GEJ adenocarcinoma treated with preoperative chemotherapy \pm RT followed by $\mathrm{R} 0$ resection $(17 \%$ with prior chemoradiation and $4 \%$ with chemotherapy alone). Importantly, despite achieving a pCR with preoperative therapy and independent of type of therapy, the risk of recurrence remains significant; indistinguishable from patients who were downstaged to pathologic stage I or II following preoperative therapy. There is a substantial rate of CNS first recurrences $(8 \%$ of all pCR patients and $36 \%$ of the pCR patients who developed a recurrence) in this cohort of patients, with each CNS recurrence presenting with life-threatening neurologic symptoms. 
Table 3 Timing and patterns of recurrence in patients undergoing preoperative chemotherapy \pm radiation therapy for gastric and gastrooesophageal junction adenocarcinoma, followed by R0 resection

\begin{tabular}{|c|c|c|c|}
\hline \multirow[b]{2}{*}{ Variable } & \multicolumn{2}{|c|}{ Number (\%) } & \multirow[b]{2}{*}{$P$-value } \\
\hline & $\begin{array}{c}\text { Non-pCR } \\
\text { patients } \\
(n=549)\end{array}$ & $\begin{array}{c}\text { PCR } \\
\text { patients } \\
(n=60)\end{array}$ & \\
\hline \multicolumn{4}{|l|}{ Recurrence } \\
\hline Yes & $242(44)$ & $14(23)$ & - \\
\hline \multicolumn{4}{|l|}{ Probability of recurrence } \\
\hline I year & $28 \%$ & $12 \%$ & \\
\hline 3 years & $46 \%$ & $27 \%$ & $0.01^{\mathrm{a}}$ \\
\hline 5 years & $51 \%$ & $27 \%$ & \\
\hline \multicolumn{4}{|l|}{ First recurrence location ${ }^{\mathrm{b}}$} \\
\hline Local/regional & $95(43)$ & $6(43)$ & $1.00^{c}$ \\
\hline Distant & $128(57)$ & $8(57)$ & \\
\hline CNS as site of first recurrence & $10(4)$ & $5(36)$ & $0.01^{c}$ \\
\hline
\end{tabular}

Abbreviations: $\mathrm{CNS}=$ central nervous system; $\mathrm{pCR}=$ pathologic complete response. ${ }^{a}$ Log-rank test. ${ }^{b}$ Recurrence location information available in 223 out of 242 patients (92\%) that recurred in the non-pCR patient group. ${ }^{c} \chi^{2}$ test. Bold values indicate significant differences.

The biology of tumours that completely regress with preoperative therapy is likely to be distinct from tumours that did not achieve a pCR (Ajani, 2005; Berger et al, 2005) and is reflected in RFS and OS. As demonstrated in other malignancies (Wolmark et al, 2001; Berger et al, 2005; Mamon et al, 2005; Rohatgi et al, 2005; Chen et al, 2007; Chao et al, 2009; Donahue et al, 2009; Adams et al, 2010; Maas et al, 2010; Park et al, 2010), patients with gastric/GEJ adenocarcinoma who achieve a pCR following preoperative therapy have significant improvements in 5-year OS (60 vs 35\%), DSS (67 vs 43\%), and RFS (69 vs 45\%) when compared with the group who did not achieve a pCR. However, despite achieving a pCR, we noted a significant risk of recurrence in this cohort of patients. Specifically, as shown in Figure 3, there are no differences in the probability of recurrence between the pCR and posttreatment stage I and II patients. The distribution of local/ regional (43\%) vs distant recurrence $(57 \%)$ in the pCR and nonpCR groups is identical. However, there is a significantly higher rate of CNS first recurrences in the pCR $(36 \%)$ compared with the non-pCR (4\%) cohort. The increased risk of developing CNS metastases in patients achieving a pCR is likely due to diminished penetration of the CNS by all of the chemotherapeutic agents in the treatment of gastric/GEJ cancer (Chabner and Longo, 2011). NonpCR patients, in contrast, are more likely to have persistent micrometastatic disease in systemic circulation, and are therefore more likely to have a non-CNS site of first recurrence. Although CNS recurrences may be more prevalent in patients with prolonged survival, we would highlight that in our cohort, three of the five CNS recurrences in the PCR group developed recurrence early (i.e., $<13$ months) in their postoperative period, making our findings more noteworthy. It is well established that CNS metastases occur in $\sim 50 \%$ of patients with locally advanced nonsmall-cell lung cancer (NSCLC) (Mamon et al, 2005). In patients with NSCLC treated with preoperative chemoradiation that have a pCR at the time of resection, there remains a $43 \%$ rate of CNS metastases as the site of first failure, which represents $71 \%$ of all isolated recurrences (Chen et al, 2007). This observation has led to the use of prophylactic cranial irradiation in patients with stage III NSCLC treated with preoperative chemoradiotherapy and curative surgery, a strategy that has significantly reduced the risk of CNS metastases (18.0 vs $7.7 \%$, unadjusted odds ratio $=2.52, P=0.004)$. However, this strategy has not improved OS or DFS (Gore et al, 2011). The rate of CNS recurrence in NSCLC

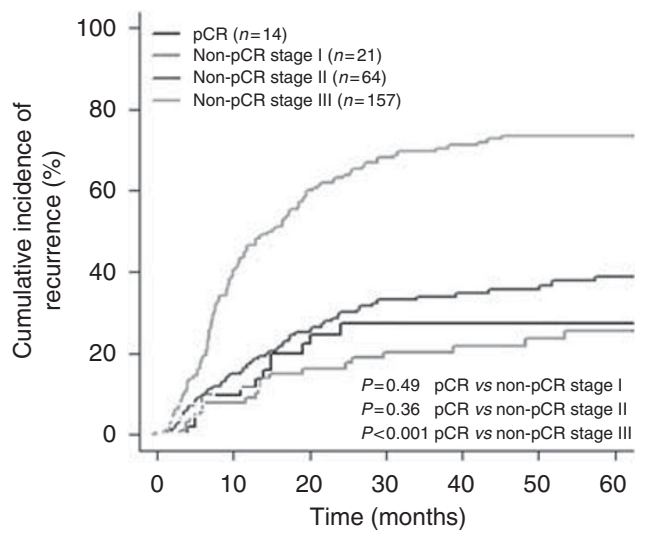

\begin{tabular}{lccc}
\hline \multirow{2}{*}{ Stage } & \multicolumn{3}{c}{ Probability of recurrence } \\
\cline { 2 - 4 } & 1 year & 3 year & 5 year \\
\hline \multirow{2}{*}{ (pCR) } & $12 \%$ & $27 \%$ & $27 \%$ \\
1 (Non-pCR stage 1) & $9 \%$ & $20 \%$ & $25 \%$ \\
2 (Non-pCR stage 2) & $17 \%$ & $34 \%$ & $39 \%$ \\
3 (Non-pCR stage 3) & $57 \%$ & $70 \%$ & $74 \%$ \\
\hline
\end{tabular}

Figure 3 Cumulative incidences and probabilities of recurrence by stage (treating death from other causes as a competing risk) in patients undergoing preoperative chemotherapy \pm radiation therapy for gastric and gastrooesophageal junction adenocarcinoma, followed by RO resection. Abbreviations: $p C R=$ pathologic complete response, non-pCR $=$ nonpathologic complete response.

is substantially higher than the $8 \%$ rate of CNS as the site of first failure in patients with gastric/GEJ adenocarcinoma who achieved a pCR following preoperative therapy, suggesting a limited value of prophylactic whole brain radiation in this select population.

Interestingly, patients with a pCR had higher numbers of LNs examined in the pathologic specimen when compared with non-pCR patients (29 vs 23). In rectal cancer, it is suggested that interactions between tumour and host immune cells may be different between pCR and non-pCR tumours (Ogino et al, 2010). Increased LN count, and in particular increased negative LN count, has been found to be associated with increased survival in colorectal cancer (Chang et al, 2007). Patients who achieve a pCR may elicit a stronger immune response, resulting in more numerous and larger regional LN, suggesting a possible biologic/ immunologic difference in the host response to these tumours (Johnson et al, 2006; Ogino et al, 2010). The low frequency of pCR and varied overall histologic response rates to preoperative therapy highlight the importance of ongoing research to identify response to therapy early. We and others have examined FDGPET/CT for this purpose (Lordick et al, 2007; Shah, 2007; Ott et al, 2008; Wieder and Weber, 2009). A presently accruing study at our institution is studying the ability of FDG-PET to discriminate responders $v s$ non-responders to preoperative chemotherapy for locally advanced gastric cancer and to salvage non-responding patients with alternate chemotherapy (Shah, 2011).

This retrospective evaluation reflects the current multidisciplinary approach to patients with gastric cancer in which proximal gastric tumours (Siewert type II or III) may receive either chemotherapy alone or combined modality chemoradiation before surgical resection. Our data are not intended to compare and contrast the merits of these two distinct treatment approaches, but rather are focused on the risk and pattern of recurrence of patients who achieve a significant and complete pathologic response to preoperative therapy. Notably, we did not observe a difference in recurrence rate between those receiving chemoradiotherapy (26\%) and those receiving chemotherapy alone (15\%). This may, in part, 
Table 4 Location and timing of first recurrence in 14 of 60 (23\%) patients following a pathologic complete response to neoadjuvant chemotherapy \pm radiation therapy for gastric or gastrooesophageal junction adenocarcinoma

\begin{tabular}{|c|c|c|c|c|}
\hline $\begin{array}{l}\text { Recurrence } \\
\text { location }\end{array}$ & $\begin{array}{l}\text { Time to recurrence } \\
\text { (months) }\end{array}$ & Treatment & $\begin{array}{l}\text { Status at last } \\
\text { follow-up }\end{array}$ & $\begin{array}{l}\text { Time from recurrence to death } \\
\text { or last follow-up (months) }\end{array}$ \\
\hline CNS & 15 & None & DOD & । \\
\hline $\mathrm{CNS}^{\mathrm{a}}$ & 5 & Whole brain RT & DOD & 17 \\
\hline CNS & 6 & Whole brain RT & DOD & 2 \\
\hline CNS, liver ${ }^{a}$ & 24 & None & DOD & 2 \\
\hline Liver & 5 & Platinum/CPTII & DOD & 12 \\
\hline Regional LN & 19 & Platinum/Taxol & AWD & 27 \\
\hline Regional LN & 11 & Taxol & DOD & 36 \\
\hline Local & 20 & Taxol & DOD & 24 \\
\hline Local & 14 & Surgery & DOD & 1 \\
\hline Local & 6 & Taxol/CPTII & DOD & 11 \\
\hline Local & 15 & Taxol/CPTII & DOD & 10 \\
\hline
\end{tabular}

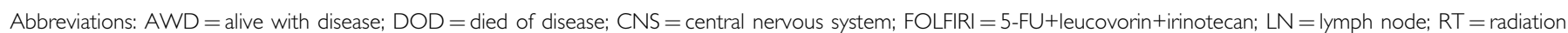
therapy. ${ }^{a}$ Denotes gastric primary.

be due to the low overall rate of pCR to chemotherapy alone (4\%), corresponding to our limited statistical power to compare these two groups.

We acknowledge that our observations are based on a small number of total events (i.e., 14 recurrences in 60 pCR patients, with 5 CNS recurrences). However, to our knowledge this represents the largest reported series describing patients with a pCR after preoperative treatment and surgical resection in gastric/ GEJ adenocarcinoma. All of the patients with CNS metastases presented with symptomatic seizures or neurologic symptoms. Early detection of brain metastases may identify these patients before they experience seizures or symptoms and allow for early treatment (stereotactic RT and/or surgery). These data support having an increased awareness of the risk of the CNS as the first site of recurrence in this cohort of patients. Considering that all CNS metastases developed within 2 years of follow-up (range 5-24 months), selective surveillance brain imaging (contrast enhanced CT or MRI) to identify CNS disease before the onset of symptoms during the first 2 years of follow-up would be reasonable. Additionally, we noted that despite achieving a pCR, there was a $43 \%$ incidence of local/regional recurrence. Four patients $(7 \%$ of all pCR patients and $29 \%$ of all pCR recurrences) developed a local recurrence as the site of first recurrence. Thus, pCR does not

\section{REFERENCES}

Adams S, Chakravarthy AB, Donach M, Spicer D, Lymberis S, Singh B, Bauer JA, Hochman T, Goldberg JD, Muggia F, Schneider RJ, Pietenpol JA, Formenti SC (2010) Preoperative concurrent paclitaxel-radiation in locally advanced breast cancer: pathologic response correlates with five-year overall survival. Breast Cancer Res Treat 124(3): 723-732

Ajani JA (2005) Carcinoma of the esophagus: is biology screaming in my deaf ears? J Clin Oncol 23(19): 4256-4258

Anderson SE, Minsky BD, Bains M, Hummer A, Kelsen D, Ilson DH (2007) Combined modality chemoradiation in elderly oesophageal cancer patients. Br J Cancer 96(12): $1823-1827$

Anderson WF, Camargo MC, Fraumeni Jr JF, Correa P, Rosenberg PS, Rabkin CS (2010) Age-specific trends in incidence of noncardia gastric cancer in US adults. JAMA 303(17): 1723-1728

Bains MS, Stojadinovic A, Minsky B, Rusch V, Turnbull A, Korst R, Ginsberg R, Kelsen DP, Ilson DH (2002) A phase II trial of preoperative combined-modality therapy for localized esophageal carcinoma: initial results. J Thorac Cardiovasc Surg 124(2): $270-277$

Berger AC, Farma J, Scott WJ, Freedman G, Weiner L, Cheng JD, Wang $\mathrm{H}$, Goldberg $\mathrm{M}$ (2005) Complete response to neoadjuvant obviate the need for continued local-regional surveillance of this patient cohort.

In summary, $\mathrm{pCR}$ following preoperative chemotherapy $\pm \mathrm{RT}$ followed by surgical resection for gastric/GEJ adenocarcinoma occurs in a minority of patients. When compared with non-pCR patients, a pCR results in improved survival; however, there remains a significant rate of recurrence. Patients that achieve a pCR after preoperative therapy have a similar risk of recurrence to posttreatment pathological stage I and II tumours. In addition, there is a significantly higher incidence of symptomatic CNS first recurrences in pCR patients. These findings have important clinical implications: care providers should be cognizant of the risk of symptomatic CNS recurrences in this select cohort of patients and should consider selective brain imaging for early identification and treatment of CNS metastases.

\section{ACKNOWLEDGEMENTS}

We acknowledge ASCO Career Development Award (MAS), FDA Orphan Disease Product Grant 1R01FD003755-01A1 (MAS), NCI Contract N01 CM62206 (DPK), and DeGregorio Family Foundation (MAS). chemoradiotherapy in esophageal carcinoma is associated with significantly improved survival. J Clin Oncol 23(19): 4330-4337

Brenner B, Ilson DH, Minsky BD, Bains MS, Tong W, Gonen M, Kelsen DP (2004) Phase I trial of combined-modality therapy for localized esophageal cancer: escalating doses of continuous-infusion paclitaxel with cisplatin and concurrent radiation therapy. J Clin Oncol 22(1): 45-52

Brenner B, Shah MA, Karpeh MS, Gonen M, Brennan MF, Coit DG, Klimstra DS, Tang LH, Kelsen DP (2006) A phase II trial of neoadjuvant cisplatin-fluorouracil followed by postoperative intraperitoneal floxuridine-leucovorin in patients with locally advanced gastric cancer. Ann Oncol 17(9): 1404-1411

Chabner B, Longo DL (2011) Cancer Chemotherapy and Biotherapy: Principles and Practice, 5th edn Wolters Kluwer/Lippincott Williams \& Wilkins Health: Philadelphia

Chang GJ, Rodriguez-Bigas MA, Skibber JM, Moyer VA (2007) Lymph node evaluation and survival after curative resection of colon cancer: systematic review. J Natl Cancer Inst 99(6): 433-441

Chao YK, Chan SC, Liu YH, Chen HW, Wan YL, Chang HK, Fan KH, Liu HP (2009) Pretreatment T3-4 stage is an adverse prognostic factor in 
patients with esophageal squamous cell carcinoma who achieve pathological complete response following preoperative chemoradiotherapy. Ann Surg 249(3): 392-396

Chavez-Macgregor M, Litton J, Chen H, Giordano SH, Hudis CA, Wolff AC, Valero V, Hortobagyi GN, Bondy ML, Gonzalez-Angulo AM (2010) Pathologic complete response in breast cancer patients receiving anthracycline- and taxane-based neoadjuvant chemotherapy: evaluating the effect of race/ethnicity. Cancer 116(17): 4168-4177

Chen AM, Jahan TM, Jablons DM, Garcia J, Larson DA (2007) Risk of cerebral metastases and neurological death after pathological complete response to neoadjuvant therapy for locally advanced nonsmall-cell lung cancer: clinical implications for the subsequent management of the brain. Cancer 109(8): $1668-1675$

Cunningham D, Allum WH, Stenning SP, Thompson JN, Van de Velde CJ, Nicolson M, Scarffe JH, Lofts FJ, Falk SJ, Iveson TJ, Smith DB, Langley RE, Verma M, Weeden S, Chua YJ, Participants MT (2006) Perioperative chemotherapy versus surgery alone for resectable gastroesophageal cancer. $N$ Engl J Med 355(1): 11-20

Donahue JM, Nichols FC, Li Z, Schomas DA, Allen MS, Cassivi SD, Jatoi A, Miller RC, Wigle DA, Shen KR, Deschamps C (2009) Complete pathologic response after neoadjuvant chemoradiotherapy for esophageal cancer is associated with enhanced survival. Ann Thorac Surg 87(2): 392-398; discussion 398-399

Edge SB, Byrd DR, Compton CC, Fritz AG, Greene FL, Trotti A (2010) AJCC Cancer Staging Manual, 7th edn Springer Science and Business Media LLC (SBM: New York)

Gore EM, Bae K, Wong SJ, Sun A, Bonner JA, Schild SE, Gaspar LE, Bogart JA, Werner-Wasik M, Choy H (2011) Phase III comparison of prophylactic cranial irradiation versus observation in patients with locally advanced non-small-cell lung cancer: Primary Analysis of Radiation Therapy Oncology Group Study RTOG 0214. J Clin Oncol 29(3): 272-278

Gray RJ (1988) A class of K-sample tests for comparing the cumulative incidence of a competing risk. Ann Stat 16(3): 1141-1154

Habr-Gama A, Perez RO, Nadalin W, Sabbaga J, Ribeiro Jr U, Silva e Sousa Jr AH, Campos FG, Kiss DR, Gama-Rodrigues J (2004) Operative versus nonoperative treatment for stage 0 distal rectal cancer following chemoradiation therapy: long-term results. Ann Surg 240(4): 711-717; discussion $717-718$

Hundahl SA, Phillips JL, Menck HR (2000) The National Cancer Data Base Report on poor survival of U.S. gastric carcinoma patients treated with gastrectomy: Fifth Edition American Joint Committee on Cancer staging, proximal disease, and the 'different disease' hypothesis. Cancer 88(4): $921-932$

Jemal A, Siegel R, Xu J, Ward E (2010) Cancer statistics, 2010. CA Cancer J Clin 60(5): 277-300

Johnson PM, Porter GA, Ricciardi R, Baxter NN (2006) Increasing negative lymph node count is independently associated with improved long-term survival in stage IIIB and IIIC colon cancer. J Clin Oncol 24(22): $3570-3575$

Kamangar F, Dores GM, Anderson WF (2006) Patterns of cancer incidence, mortality, and prevalence across five continents: defining priorities to reduce cancer disparities in different geographic regions of the world. $J$ Clin Oncol 24(14): $2137-2150$

Kaplan E, Meier P (1958) Nonparametric estimation from incomplete observations. J Am Stat Assoc 53: 457-481

Kelsen D, Atiq OT, Saltz L, Niedzwiecki D, Ginn D, Chapman D, Heelan R, Lightdale C, Vinciguerra V, Brennan M (1992) FAMTX versus etoposide, doxorubicin, and cisplatin: a random assignment trial in gastric cancer. $J$ Clin Oncol 10(4): $541-548$

Kelsen D, Ginsberg R, Bains M, Cooper J, Arquette M, Forastiere AA, Ilson D (1997) A phase II trial of paclitaxel and cisplatin in patients with locally advanced metastatic esophageal cancer: a preliminary report. Semin Oncol 24(6 Suppl 19): S19-77-S19-81

Lordick F, Ott K, Krause BJ, Weber WA, Becker K, Stein HJ, Lorenzen S, Schuster T, Wieder H, Herrmann K, Bredenkamp R, Hofler H, Fink U, Peschel C, Schwaiger M, Siewert JR (2007) PET to assess early metabolic response and to guide treatment of adenocarcinoma of the oesophagogastric junction: the MUNICON phase II trial. Lancet Oncol 8(9): 797-805

Maas M, Nelemans PJ, Valentini V, Das P, Rodel C, Kuo LJ, Calvo FA, Garcia-Aguilar J, Glynne-Jones R, Haustermans K, Mohiuddin M, Pucciarelli S, Small Jr W, Suarez J, Theodoropoulos G, Biondo S, Beets-Tan RG, Beets GL (2010) Long-term outcome in patients with a pathological complete response after chemoradiation for rectal cancer: a pooled analysis of individual patient data. Lancet Oncol 11(9): $835-844$

Macdonald JS, Smalley SR, Benedetti J, Hundahl SA, Estes NC, Stemmermann GN, Haller DG, Ajani JA, Gunderson LL, Jessup JM, Martenson JA (2001) Chemoradiotherapy after surgery compared with surgery alone for adenocarcinoma of the stomach or gastroesophageal junction. N Engl J Med 345(10): 725-730

Mamon HJ, Yeap BY, Janne PA, Reblando J, Shrager S, Jaklitsch MT, Mentzer S, Lukanich JM, Sugarbaker DJ, Baldini EH, Berman S, Skarin A, Bueno R (2005) High risk of brain metastases in surgically staged IIIA non-small-cell lung cancer patients treated with surgery, chemotherapy, and radiation. J Clin Oncol 23(7): $1530-1537$

Mansour JC, Tang L, Shah M, Bentrem D, Klimstra DS, Gonen M, Kelsen DP, Brennan MF, Coit DG (2007) Does graded histologic response after neoadjuvant chemotherapy predict survival for completely resected gastric cancer? Ann Surg Oncol 14(12): 3412-3418

Ogino S, Nosho K, Irahara N, Shima K, Baba Y, Kirkner GJ, Mino-Kenudson M, Giovannucci EL, Meyerhardt JA, Fuchs CS (2010) Negative lymph node count is associated with survival of colorectal cancer patients, independent of tumoral molecular alterations and lymphocytic reaction. Am J Gastroenterol 105(2): 420-433

Ott K, Herrmann K, Lordick F, Wieder H, Weber WA, Becker K, Buck AK, Dobritz M, Fink U, Ulm K, Schuster T, Schwaiger M, Siewert JR, Krause BJ (2008) Early metabolic response evaluation by fluorine-18 fluorodeoxyglucose positron emission tomography allows in vivo testing of chemosensitivity in gastric cancer: long-term results of a prospective study. Clin Cancer Res 14(7): 2012-2018

Park JW, Kim JH, Choi EK, Lee SW, Yoon SM, Song SY, Lee YS, Kim SB, Park SI, Ahn SD (2010) Prognosis of esophageal cancer patients with pathologic complete response after preoperative concurrent chemoradiotherapy. Int J Radiat Oncol Biol Phys; e-pub ahead of print 30 September 2010

Prentice RL, Kalbfleisch JD, Peterson Jr AV, Flournoy N, Farewell VT, Breslow NE (1978) The analysis of failure times in the presence of competing risks. Biometrics 34(4): $541-554$

Pucciarelli S, Toppan P, Friso ML, Russo V, Pasetto L, Urso E, Marino F, Ambrosi A, Lise M (2004) Complete pathologic response following preoperative chemoradiation therapy for middle to lower rectal cancer is not a prognostic factor for a better outcome. Dis Colon Rectum 47(11): $1798-1807$

Reed VK, Krishnan S, Mansfield PF, Bhosale PR, Kim M, Das P, Janjan NA, Delclos ME, Lowy AM, Feig BW, Pisters PW, Ajani JA, Crane CH (2008) Incidence, natural history, and patterns of locoregional recurrence in gastric cancer patients treated with preoperative chemoradiotherapy. Int J Radiat Oncol Biol Phys 71(3): 741-747

Rohatgi PR, Swisher SG, Correa AM, Wu TT, Liao Z, Komaki R, Walsh G, Vaporciyan A, Lynch PM, Rice DC, Roth JA, Ajani JA (2005) Failure patterns correlate with the proportion of residual carcinoma after preoperative chemoradiotherapy for carcinoma of the esophagus. Cancer 104(7): 1349 - 1355

Satagopan JM, Ben-Porat L, Berwick M, Robson M, Kutler D, Auerbach AD (2004) A note on competing risks in survival data analysis. Br J Cancer 91(7): $1229-1235$

Schuhmacher C, Gretschel S, Lordick F, Reichardt P, Hohenberger W, Eisenberger CF, Haag C, Mauer ME, Hasan B, Welch J, Ott K, Hoelscher A, Schneider PM, Bechstein W, Wilke H, Lutz MP, Nordlinger B, Cutsem EV, Siewert JR, Schlag PM (2010) Neoadjuvant chemotherapy compared with surgery alone for locally advanced cancer of the stomach and cardia: European Organisation for Research and Treatment of Cancer randomized trial 40954. J Clin Oncol 28(35): $5210-5218$

Schwartz GK, Winter K, Minsky BD, Crane C, Thomson PJ, Anne P, Gross H, Willett C, Kelsen D (2009) Randomized phase II trial evaluating two paclitaxel and cisplatin-containing chemoradiation regimens as adjuvant therapy in resected gastric cancer (RTOG-0114). J Clin Oncol 27(12): $1956-1962$

Shah MA (2007) A phase II study of preoperative chemotherapy with irinotecan (CPT) and cisplatin (CIS) for gastric cancer (NCI 5917): FDGPET/CT predicts patient outcome. ASCO Annu Meet

Shah MA (2011) Pre-operative chemotherapy plus bevacizumab with early salvage therapy based on PET assessment of response in patients with locally advanced but resectable gastric and GEJ adenocarcinoma (clinicaltrials.gov NCT00737438). http://clinicaltrials.gov/ct2/show/ NCT00737438?term=pre-operative+chemotherapy+plus+bevacizumab\&rank=1

Shah MA, Ajani JA (2010) Gastric cancer-an enigmatic and heterogeneous disease. JAMA 303(17): 1753-1754 
Stahl M, Walz MK, Stuschke M, Lehmann N, Meyer HJ, Riera-Knorrenschild J, Langer $P$, Engenhart-Cabillic R, Bitzer $M$, Konigsrainer A, Budach W, Wilke H (2009) Phase III comparison of preoperative chemotherapy compared with chemoradiotherapy in patients with locally advanced adenocarcinoma of the esophagogastric junction. J Clin Oncol 27(6): 851-856

Symmans WF, Peintinger F, Hatzis C, Rajan R, Kuerer H, Valero V, Assad L, Poniecka A, Hennessy B, Green M, Buzdar AU, Singletary SE, Hortobagyi GN, Pusztai L (2007) Measurement of residual breast cancer burden to predict survival after neoadjuvant chemotherapy. J Clin Oncol 25(28): 4414-4422
Wieder H, Weber W (2009) Prediction of tumour response by FDG-PET in patients with adenocarcinomas of the oesophagogastric junction. Eur J Nucl Med Mol Imaging 36(1): 158-159

Wolmark N, Wang J, Mamounas E, Bryant J, Fisher B (2001) Preoperative chemotherapy in patients with operable breast cancer: nine-year results from National Surgical Adjuvant Breast and Bowel Project B-18. J Natl Cancer Inst Monogr 30: 96-102

Wu H, Rusiecki JA, Zhu K, Potter J, Devesa SS (2009) Stomach carcinoma incidence patterns in the United States by histologic type and anatomic site. Cancer Epidemiol Biomarkers Prev 18(7): 1945-1952 